\title{
Knowledge, Attitude, and Practices of dentists in offering dental treatment to pregnant women in Jordan: A Cross-Sectional survey
}

Bara' Abdallah AlShurman ( $\square$ baalshurman17@med.just.edu.jo)

Jordan University of Science and Technology https://orcid.org/0000-0002-1229-1920

Yousef Saleh Khader

Jordan University of Science and Technology

Anwar Batieha

Jordan University of Science and Technology

Ola B. Al-Batayneh

Jordan University of Science and Technology

Abd-Albaset Odat

Jordan University of Science and Technology

Mohammad Alyahya

Jordan University of Science and Technology

Mourad Dawoud

Jordan University of Science and Technology

Maria A. AlShurman

Jordan University of Science and Technology

\section{Research Article}

Keywords: Dentists' Knowledge, Pregnancy, Oral health, Dental treatment

Posted Date: September 1st, 2020

DOl: https://doi.org/10.21203/rs.3.rs-38323/v2

License: (c) (i) This work is licensed under a Creative Commons Attribution 4.0 International License.

Read Full License 


\section{Abstract}

Background: Although international guidelines emphasized that pregnant patients should receive proper dental treatment, many dentists are still hesitant to do so. This study aimed to determine the knowledge, attitude, and practices of dentists towards offering dental treatment to pregnant women in Jordan.

Methods: An online survey was distributed to 1000 dentists using social-media applications between August and October, 2019. The survey consisted of three sections; dentists' knowledge about the association between oral diseases and pregnancy, their participation in training courses, and their practices regarding various dental treatments during pregnancy. Descriptive statistics were obtained and Chi-square tests were used to measure the association between demographic variables and knowledge, attitude, and practices variables. Significance was considered at P-value $<0.05$.

Results: A total of $547(54.7 \%)$ responded to the questionnaire. Only (37.5\%) agreed that periodontal diseases might increase risk of adverse pregnancy outcomes. Almost (75.9\%) did not attend any training program. The 2 nd trimester was the most preferable time to do all dental procedures. There was a tendency to perform scaling and fillings especially in the 2nd trimester (82.4\%), (86.1\%) respectively. The majority of dentists would feel comfortable to do RCT $(72.0 \%)$ or extraction $(60.0 \%)$ in the $2^{\text {nd }}$ trimester, whereas greater caution was apparent on $1^{\text {st }}$ and $3^{\text {rd }}$ trimester. A proportion of $(32.5 \%)$ thought that taking $x$-rays during pregnancy was contraindicated. About (53.7\%) didn't know about the safety to administer nitrous oxide sedation during pregnancy. Around (75.9\%) refused to prescribe non-steroidal anti-inflammatory drugs to pregnant women. By far, paracetamol was the drug of choice $(96.9 \%)$ to prescribe as an analgesic and amoxicillin as an antibiotic (89.2\%).

Conclusion: lack of knowledge, poor attitude and incorrect practices were observed among surveyed dentists with regards to management of pregnant women. Thus, further education courses about international guidelines are needed to correct the common misconceptions and negative attitudes and practices of dentists in treating pregnant women.

\section{Background}

The physiological and hormonal changes occurring during pregnancy may adversely affect oral and dental health and result in noticeable alterations in the oral cavity (1). Most of these changes include gingivitis, periodontitis, pyogenic granuloma, benign oral lesions, tooth erosion, and dental caries (2).

A significant proportion of public as well as health professionals believe that dental treatment can harm the embryo and this prevents many women from seeking dental care, thus neglect their oral health (3). Previous investigations revealed a high level of unawareness and ignorance among most pregnant women who did not seek necessary dental treatment (4-7). One study showed low rates of dental attendance among post-partum pregnant women within the past six months because of their biggest worries about fetal safety during dental procedures followed by their financial situations (8). 
Dentists often encounter pregnant patients in dental clinics, and are usually hesitant to provide suitable dental treatment due to fearfulness and uncertainty about the risks that will face both the mother and fetus. Several studies have reported that the majority of dental practitioners were inadequately educated during their undergraduate studies in providing treatment to pregnant women $(3,9,10)$. In order to help dentists face their anxiety and make right decisions in treating pregnant women, international guidelines and protocols should be followed with regards to different dental procedures such as fillings, root canal treatment, radiographs, periodontal treatment, extraction, local anesthesia, medications and women's sitting position on the dental chair.

Several guidelines and protocols were produced by scientific organizations to provide evidence-based answers about frequent dilemmas of dentists concerning dental treatment of pregnant women. Many organizations including the American Dental Association (ADA), the American Pregnancy Association (APA), the American Academy of Pediatric Dentistry (AAPD), American College of Obstetricians and Gynecologists (ACOG), and the Food and Drug Administration (FDA) have developed protocols and conventions in order to improve the oral well-being of pregnant women and babies (11-16). They stressed on that pregnancy is not an illness; thus, pregnant women should not be treated differently than the general population (17).

In Jordan, there have been no official guidelines and protocols for dental treatment among pregnant women. There are no studies published in Jordan that assessed the extent of dental practitioners' knowledge regarding the provision of dental treatment during pregnancy. Assessing dentists' knowledge and practices toward pregnant women could help create an advanced oral health-care package for pregnant women in collaboration with stakeholders in maternal health-care, which is necessary for dentists who work in Jordan. As well, this will reduce the gap in knowledge, correct negative attitudes, and optimize preventive and interventional dental treatment approaches among oral health givers (2). This study aimed to assess dentists' knowledge about oral health care during pregnancy, determine their attitudes towards offering dental treatment to pregnant women and to assess their practices in providing dental care to pregnant women.

\section{Methods}

\section{Study design and sampling}

This cross-sectional study was conducted between August and October 2019 among dentists who work in Jordan who have finished their internship year regardless of their place of work. A sample of dentists was recruited using professional Facebook groups. The approached groups on Facebook included dentists from different governorates mainly Amman, Irbid, Jerash, Karak, and Zarqa where the population concentrated. These groups were created by members of Jordan Dental Association, and only dentists who work in Jordan can be involved in these groups by confirming accurate information about their places of work. Although there were numerous groups, only 5 groups were randomly chosen; Jordanian dentists (https://www.facebook.com/groups/642593455757705/) , Dentists without borders 
(https://www.facebook.com/groups/215931198483242/), Jordanian dental club (https://www.facebook.com/groups/631589300357295/), Jordanian society of pediatric dentistry (https://www.facebook.com/groups/385574841855046/), and Jordanian dental scientific forum(https://www.facebook.com/groups/1926694694238335/). From each group of the 5 nominated ones, 200 dentists were randomly selected from the members' list to participate in the study by their Facebook profiles. Each participant was contacted individually to make sure that he/she is a dentist and works in Jordan. One thousand online forms were distributed through Messenger-app in August 2019. After two months, only 547 responded and completed the online questionnaire. The questionnaires were anonymous to maintain the privacy and confidentiality of all information collected in the study. This sample size was enough to assess in the most conservative way of the study variables with a margin of error not exceeding (4.2\%) using a (95.0\%) confidence level. Approval to conduct the study was granted from the IRB (Institutional review board) at Jordan University of Science and Technology.

\section{Survey instrument}

A self-administrated questionnaire was developed based on the literature review and the international guidelines to offer proper dental treatment to pregnant women $(12,18-20)$. The questionnaire was designed in English language and comprised a series of questions pertaining to socio-demographic characteristics, knowledge of dentists, their attitudes, and practices in management of pregnant dental patients.

The questionnaire comprised 32 close-ended questions organized into four categories: Demographic variables, knowledge of dentists about the treatment of pregnant women, attitudes of dentists regarding the treatment of pregnant women, and practices of dentists regarding the treatment of pregnant women.

The demographic portion of the instrument included questions on gender, age, nationality, specialty, number of years in clinical practice, place of practice, and previous experience in treating pregnant women. The second section covered the knowledge among dentists about the relationship between oral health and adverse pregnancy outcomes. The third one covered the attitude of dentists toward pregnant women based on participating in previous educational courses or receiving enough information about dental treatment for pregnant women. The last section included two parts; the first one appeared as a table with 4 questions to assess the provision of dental treatment such as scaling, fillings, root canal treatment, and extraction during pregnancy, whereas the second part assessed dentists' thoughts about the safest trimester to provide treatment, radiographic examination, local anesthesia, the position of pregnant women on a dental chair, nitrous oxide sedation, and selected therapeutic choices like antibiotics, analgesics, and nonsteroidal anti-inflammatory drugs.

Likert scale was used to record the responses on the questions in knowledge section (strongly agree, agree, neutral, disagree, and strongly disagree). The responses for questions about the dentists' practices included four responses: treating her, referral to a specialist, consulting a gynecologist, and postponing the treatment to after delivery. 


\section{Data analysis}

Data were analyzed using IBM SPSS, version 24. Data were described using percentages and means. Chisquare test was used to compare percentages. A P-value of less than 0.05 was considered significant.

\section{Results}

\section{Demographic and work related characteristics}

Of the 547 dentists, 236(43.1\%) were males. Most of the respondents were Jordanian dentists (94.9\%). Almost half (47.5\%) of dentists aged 20-30 years, and (52.5\%) aged more than 30 years old. More than half (54.5\%) of the respondents were general practitioners and had an experience of more than five years (53.6\%) (Table 1).

Table 1. The demographic characteristics of 547 dentists in Jordan, 2020

\begin{tabular}{|l|l|c|}
\hline Variable & Female & N (\%) \\
\cline { 2 - 3 } & Male & $311(56.9)$ \\
\hline \multirow{4}{*}{ Nationality } & Jordanian & $236(43.1)$ \\
\cline { 2 - 3 } & Others & $519(94.9)$ \\
\hline \multirow{5}{*}{ Speciality } & $20-30$ & $28(5.1)$ \\
\cline { 2 - 3 } & $31-40$ & $260(47.5)$ \\
\cline { 2 - 3 } & $41-50$ & $175(32.0)$ \\
\cline { 2 - 3 } & $>50$ & $92(16.8)$ \\
\hline \multirow{5}{*}{ Practice } & GP & $20(3.7)$ \\
\cline { 2 - 3 } & Prosthodontist & $298(54.5)$ \\
\cline { 2 - 3 } & Endodontist & $32(5.9)$ \\
\cline { 2 - 3 } & Periodontist & $29(5.3)$ \\
\cline { 2 - 3 } & Maxillofacialsurgeon & $37(6.8)$ \\
\cline { 2 - 3 } & Others & $107(8.0)$ \\
\hline \multirow{5}{*}{ Number of years in clinical practice } & Hospitals & $147(26.9)$ \\
\cline { 2 - 3 } & Health centers & $75(13.7)$ \\
\cline { 2 - 3 } & Private clinics & $258(47.2)$ \\
\cline { 2 - 3 } & Both public and private & $67(12.2)$ \\
\cline { 2 - 3 } & $1-5$ & $254(46.4)$ \\
\cline { 2 - 3 } & $6-10$ & $61(106(19.4)$ \\
\cline { 2 - 3 } & $11-15$ & $49(9.0)$ \\
\cline { 2 - 3 } & $16-20$ & $61.2)$ \\
\cline { 2 - 3 } & $>20$ & \\
\hline
\end{tabular}

\section{Knowledge about the link between dental conditions and pregnancy}

The majority of the participants (91.2\%) agreed that pregnancy increases the risk of gingival inflammation. About (58.7\%) of dentists felt there was a relationship between 
dental health and adverse pregnancy outcomes; whereas only (37.5\%) agreed that periodontal diseases might increase risk of preterm birth or low birth weight. Almost (85.0\%) of the participating dentists believed that dental treatment during pregnancy would not transmit any infection to the fetus. There was no significant difference in dentists' knowledge regarding the studied relationships according to gender (Table 2).

Table 2. Knowledge of dentists about the relation between dental health and pregnancy according to gender, Jordan 2020

\begin{tabular}{|l|l|l|l|c|}
\hline Variables & Female & Male & $\begin{array}{l}\text { Total } \\
\text { n (\%) }\end{array}$ & $\begin{array}{c}\text { P- } \\
\text { value }\end{array}$ \\
\hline Pregnancy increases the risk of gingival inflammation & $\begin{array}{l}286 \\
(92.0)\end{array}$ & $\begin{array}{l}213 \\
(90.3)\end{array}$ & $\begin{array}{l}499 \\
(91.2)\end{array}$ & 0.485 \\
\hline $\begin{array}{l}\text { There is a relationship between dental health and adverse } \\
\text { pregnancy outcomes }\end{array}$ & $\begin{array}{l}177 \\
(56.9)\end{array}$ & $\begin{array}{l}144 \\
(61.0)\end{array}$ & $\begin{array}{l}321 \\
(58.7)\end{array}$ & 0.334 \\
\hline $\begin{array}{l}\text { Periodontal diseases might increase risk of preterm birth } \\
\text { or low birth weight. }\end{array}$ & $\begin{array}{l}121 \\
(38.9)\end{array}$ & $\begin{array}{l}84 \\
(35.6)\end{array}$ & $\begin{array}{l}205 \\
(37.5)\end{array}$ & 0.428 \\
\hline $\begin{array}{l}\text { There is a relationship between dental treatment and } \\
\text { infection transmission to the fetus }\end{array}$ & $\begin{array}{l}45 \\
(14.5)\end{array}$ & $\begin{array}{l}37 \\
(15.7)\end{array}$ & $\begin{array}{l}82 \\
(15.0)\end{array}$ & 0.695 \\
\hline
\end{tabular}

\section{Attitude of dentists towards participating in training courses}

The majority of dentists (80.6\%) said that they received information on dental care during pregnancy, whereas only (33.1\%) stated that the received information on managing pregnant women was enough. Almost three quarters (75.9\%) did not attend any training program. About (79.3\%) stated they have never refused to treat pregnant women. Table 4 shows educational materials and courses received by dentist about pregnancy distributed by gender. Males participated in educational courses more than females and this was significant $(\mathrm{P}=0.00)$ (Table 3). 
Table 3. Educational materials and courses received by dentist on pregnancy, Jordan 2020

\begin{tabular}{|l|c|c|c|c|}
\hline \multirow{2}{*}{ Variables } & \multicolumn{3}{|c|}{ Gender } & \multirow{2}{*}{ P-value } \\
\cline { 2 - 5 } & $\begin{array}{c}\text { Female } \\
\mathrm{n}(\%)\end{array}$ & $\begin{array}{c}\text { Male } \\
\mathrm{n}(\%)\end{array}$ & $\begin{array}{c}\text { Total } \\
(\%)\end{array}$ & \\
\hline Receiving information on dental care during pregnancy & $253(81.4)$ & $188(79.7)$ & $441(80.6)$ & 0.621 \\
\hline Participating in educational courses & & & & \\
\hline Enough information on managing pregnant women & $98(31.5)$ & $83(35.2)$ & $181(33.1)$ & 0.570 \\
\hline Refused to treat pregnant women & & & & \\
\hline
\end{tabular}

\section{Practices of different dental procedure during pregnancy}

The preferable trimester to do all procedures was the $2^{\text {nd }}$ trimester. There was a tendency among dentists to perform scaling and fillings especially in the 2nd trimester (82.4\%), (86.1\%) respectively. A higher proportion of dentists would prefer to consult gynecologist or refer to specialist in $1^{\text {st }}$ and $3^{\text {rd }}$ trimester. The majority of dentistswould feel comfortable to do RCT (72.0\%) or extraction $(60.0 \%)$ in the $2^{\text {nd }}$ trimester, whereas greater caution was apparent on $1^{\text {st }}$ and $3^{\text {rd }}$ trimester. The findings indicated that roughly more than half of the participants preferred to consult a gynecologist or refer to a specialiston the $1^{\text {st }}$ and $3^{\text {rd }}$ trimester instead of performing endodontic therapy or extraction during pregnancy (Table $4)$.

The vast majority $(89.4 \%)$ of respondents considered that $2^{\text {nd }}$ trimester is the safest period to do all dental procedures. About one-third of participants (32.5\%) indicated that x-ray is contraindicated during pregnancy, and (69.7\%) felt that it is safe to take a single periapical $\mathrm{x}$-ray rather than panoramic x-ray. Fortunately, a total of (88.5\%) were aware of the suitable position to place pregnant women on a dental chair, and (62.7\%) preferred the semi-supine position.More than three-quarters of respondents (75.7\%) reported that using local anesthesia is safe during pregnancy. More than half of the participants (53.7\%) did 
not know whether it is safe to administer nitrous oxide sedation or not during pregnancy (Table 5).

In terms of medications, (37.1\%) of the respondents would prefer to prescribe medication on $2^{\text {nd }}$ trimester, and (36.9\%) agreed to use proper drugs at any stage during pregnancy. Amoxicillin was chosen as the safest antibiotic during pregnancy for (89.2\%) of participating dentists and (96.9\%) preferred paracetamol as the safest analgesic. About (75.9\%) of the participants reported that it is not safe to prescribe non-steroidal antiinflammatory drugs to pregnant women. In contrast, (13.7\%) agreed that it is safe (Table $5)$. 
Table 4. Practice of dentists in offering different dental procedures among pregnant women during the three trimesters, Jordan 2020

\begin{tabular}{|c|c|c|c|c|}
\hline Practice & $\begin{array}{c}\text { Treat } \\
\text { her } \\
\text { n (\%) }\end{array}$ & $\begin{array}{c}\text { Referral to } \\
\text { specialist } \\
\text { n (\%) }\end{array}$ & $\begin{array}{c}\text { Consult a } \\
\text { gynecologist } \mathrm{n} \\
(\%)\end{array}$ & $\begin{array}{c}\text { Postponed after } \\
\text { delivery } \\
\mathrm{n}(\%)\end{array}$ \\
\hline \multicolumn{5}{|l|}{ Scaling } \\
\hline $\begin{array}{l}1^{\text {st }} \\
\text { trimester }\end{array}$ & $\begin{array}{c}350 \\
(64.0)\end{array}$ & 75 (13.7) & $77(14.1)$ & $45(8.2)$ \\
\hline $\begin{array}{l}2^{\text {nd }} \\
\text { trimester }\end{array}$ & $\begin{array}{c}451 \\
(82.4)\end{array}$ & $55(10.1)$ & $25(4.6)$ & $16(2.9)$ \\
\hline $\begin{array}{l}3^{\text {rd }} \\
\text { trimester }\end{array}$ & $\begin{array}{c}350 \\
(64.0)\end{array}$ & $71(13.0)$ & 57 (10.4) & 69 (12.6) \\
\hline \multicolumn{5}{|l|}{ Fillings } \\
\hline $\begin{array}{l}1^{\text {st }} \\
\text { trimester }\end{array}$ & $\begin{array}{c}371 \\
(67.8) \\
\end{array}$ & $35(6.4)$ & $76(13.9)$ & 65 (11.9) \\
\hline $\begin{array}{l}2^{\text {nd }} \\
\text { trimester }\end{array}$ & $\begin{array}{c}471 \\
(86.1)\end{array}$ & $30(5.5)$ & $21(3.8)$ & $25(4.6)$ \\
\hline $\begin{array}{l}3^{\text {rd }} \\
\text { trimester }\end{array}$ & $\begin{array}{c}376 \\
(68.7)\end{array}$ & $36(6.6)$ & 63 (11.5) & $72(13.2)$ \\
\hline \multicolumn{5}{|l|}{ RCT } \\
\hline $\begin{array}{l}1^{\text {st }} \\
\text { trimester }\end{array}$ & $\begin{array}{c}247 \\
(45.2)\end{array}$ & $127(23.2)$ & $131(23.9)$ & $42(7.7)$ \\
\hline $\begin{array}{l}2^{\text {nd }} \\
\text { trimester }\end{array}$ & $\begin{array}{c}394 \\
(72.0)\end{array}$ & $86(15.7)$ & $48(8.8)$ & $19(3.5)$ \\
\hline $\begin{array}{l}3^{\text {rd }} \\
\text { trimester }\end{array}$ & $\begin{array}{c}272 \\
(49.7)\end{array}$ & $116(21.2)$ & 95 (17.4) & $64(11.7)$ \\
\hline \multicolumn{5}{|l|}{ Extraction } \\
\hline $\begin{array}{l}1^{\text {st }} \\
\text { trimester }\end{array}$ & $\begin{array}{c}152 \\
(27.8)\end{array}$ & $153(28.0)$ & $180(32.9)$ & $62(11.3)$ \\
\hline $\begin{array}{l}2^{\text {nd }} \\
\text { trimester }\end{array}$ & $\begin{array}{c}328 \\
(60.0)\end{array}$ & 107 (19.6) & 88 (16.1) & $24(4.4)$ \\
\hline $\begin{array}{l}3^{\text {rd }} \\
\text { trimester }\end{array}$ & $\begin{array}{c}172 \\
(31.4) \\
\end{array}$ & 144 (26.3) & $138(25.2)$ & $93(17.0)$ \\
\hline
\end{tabular}


Table 5. Practice of dentists about routine and emergency oral care during pregnancy by gender, Jordan 2020

\begin{tabular}{|c|c|c|c|c|c|}
\hline \multicolumn{2}{|c|}{ Practice variables } & \multirow{2}{*}{$\begin{array}{c}\text { Female, } \\
\text { n (\%) } \\
4(1.3)\end{array}$} & \multirow{2}{*}{$\begin{array}{l}\text { Male, } \\
\mathrm{n}(\%) \\
7(3.0)\end{array}$} & \multirow{2}{*}{$\begin{array}{c}\text { Total, } \\
\text { n (\%) } \\
11(2.0)\end{array}$} & \multirow{2}{*}{$\begin{array}{c}\begin{array}{c}\text { P- } \\
\text { value }\end{array} \\
0.367\end{array}$} \\
\hline Safest period for dental treatments & 1st trimester & & & & \\
\hline & 2nd trimester & $\begin{array}{c}281 \\
(90.4)\end{array}$ & $\begin{array}{c}208 \\
(88.1)\end{array}$ & $\begin{array}{c}489 \\
(89.4)\end{array}$ & \\
\hline & 3rd trimester & $26(8.4)$ & $21(8.9)$ & $47(8.6)$ & \\
\hline \multirow[t]{5}{*}{ Safest period to take dental imaging } & 1st trimester & $2(0.6)$ & $3(1.3)$ & $5(0.9)$ & \multirow[t]{5}{*}{0.452} \\
\hline & 2nd trimester & $65(20.9)$ & $39(16.5)$ & $\begin{array}{c}104 \\
(19.0)\end{array}$ & \\
\hline & 3rd trimester & $75(24.1)$ & $62(26.3)$ & $\begin{array}{c}137 \\
(25.0)\end{array}$ & \\
\hline & $\begin{array}{c}\text { at any stage during } \\
\text { pregnancy }\end{array}$ & $64(20.6)$ & $59(25.0)$ & $\begin{array}{c}123 \\
(22.5) \\
\end{array}$ & \\
\hline & Contraindicated & $\begin{array}{c}105 \\
(33.8) \\
\end{array}$ & $73(30.9)$ & $\begin{array}{r}178 \\
(32.5) \\
\end{array}$ & \\
\hline \multirow[t]{3}{*}{ Single periapical radiograph } & Yes & $\begin{array}{c}219 \\
(70.4) \\
\end{array}$ & $\begin{array}{c}162 \\
(68.6) \\
\end{array}$ & $\begin{array}{r}381 \\
(69.7) \\
\end{array}$ & \multirow[t]{3}{*}{0.184} \\
\hline & No & $55(17.7)$ & $54(22.9)$ & $\begin{array}{c}109 \\
(19.9)\end{array}$ & \\
\hline & Don't know & $37(11.9)$ & $20(8.5)$ & $57(10.4)$ & \\
\hline \multirow[t]{3}{*}{ Panoramic radiograph } & Yes & $\begin{array}{c}100 \\
(32.2)\end{array}$ & $80(33.9)$ & $\begin{array}{c}180 \\
(32.9)\end{array}$ & \multirow[t]{3}{*}{0.098} \\
\hline & No & $\begin{array}{c}147 \\
(47.3) \\
\end{array}$ & $\begin{array}{c}124 \\
(52.5) \\
\end{array}$ & $\begin{array}{c}271 \\
(49.5) \\
\end{array}$ & \\
\hline & Don't know & $64(20.6)$ & $32(13.6)$ & $96(17.6)$ & \\
\hline \multirow[t]{3}{*}{ Awareness of pregnant position } & Yes & $\begin{array}{r}277 \\
(89.1) \\
\end{array}$ & $\begin{array}{r}207 \\
(87.7) \\
\end{array}$ & $\begin{array}{c}484 \\
(88.5) \\
\end{array}$ & \multirow[t]{3}{*}{0.401} \\
\hline & No & $25(8.0)$ & $17(7.2)$ & $42(7.7)$ & \\
\hline & Don't know & $9(2.9)$ & $12(5.1)$ & $21(3.8)$ & \\
\hline \multirow[t]{4}{*}{ The most suitable position } & Supine & $13(4.2)$ & $14(5.9)$ & $27(4.9)$ & \multirow[t]{4}{*}{0.363} \\
\hline & semi supine & $\begin{array}{c}198 \\
(63.7) \\
\end{array}$ & $\begin{array}{r}145 \\
(61.4) \\
\end{array}$ & $\begin{array}{c}343 \\
(62.7)\end{array}$ & \\
\hline & 90 degree & $\begin{array}{r}981 \\
(26.0) \\
\end{array}$ & $55(23.3)$ & $\begin{array}{c}136 \\
(24.9) \\
\end{array}$ & \\
\hline & Don't know & $19(6.1)$ & $22(9.3)$ & $41(7.5)$ & \\
\hline \multirow[t]{3}{*}{ Local anesthetics } & Yes & $\begin{array}{c}230 \\
(74.0) \\
\end{array}$ & $\begin{array}{c}184 \\
(78.0) \\
\end{array}$ & $\begin{array}{c}414 \\
(75.7) \\
\end{array}$ & \multirow[t]{3}{*}{0.431} \\
\hline & No & $68(21.9)$ & $46(19.5)$ & $\begin{array}{c}114 \\
(20.8) \\
\end{array}$ & \\
\hline & Don't know & $13(4.2)$ & $6(2.5)$ & $19(3.5)$ & \\
\hline \multirow{4}{*}{$\begin{array}{l}\text { Safest trimester to use local } \\
\text { anesthetics }\end{array}$} & 1st trimester & $3(1.0)$ & $4(1.7)$ & $7(1.3)$ & \multirow[t]{4}{*}{0.662} \\
\hline & 2nd trimester & $\begin{array}{c}158 \\
(50.8) \\
\end{array}$ & $\begin{array}{c}122 \\
(51.7) \\
\end{array}$ & $\begin{array}{r}280 \\
(51.2) \\
\end{array}$ & \\
\hline & 3rd trimester & $18(5.8)$ & $9(3.8)$ & $27(4.9)$ & \\
\hline & at any stage during & 125 & $98(41.5)$ & 223 & \\
\hline
\end{tabular}




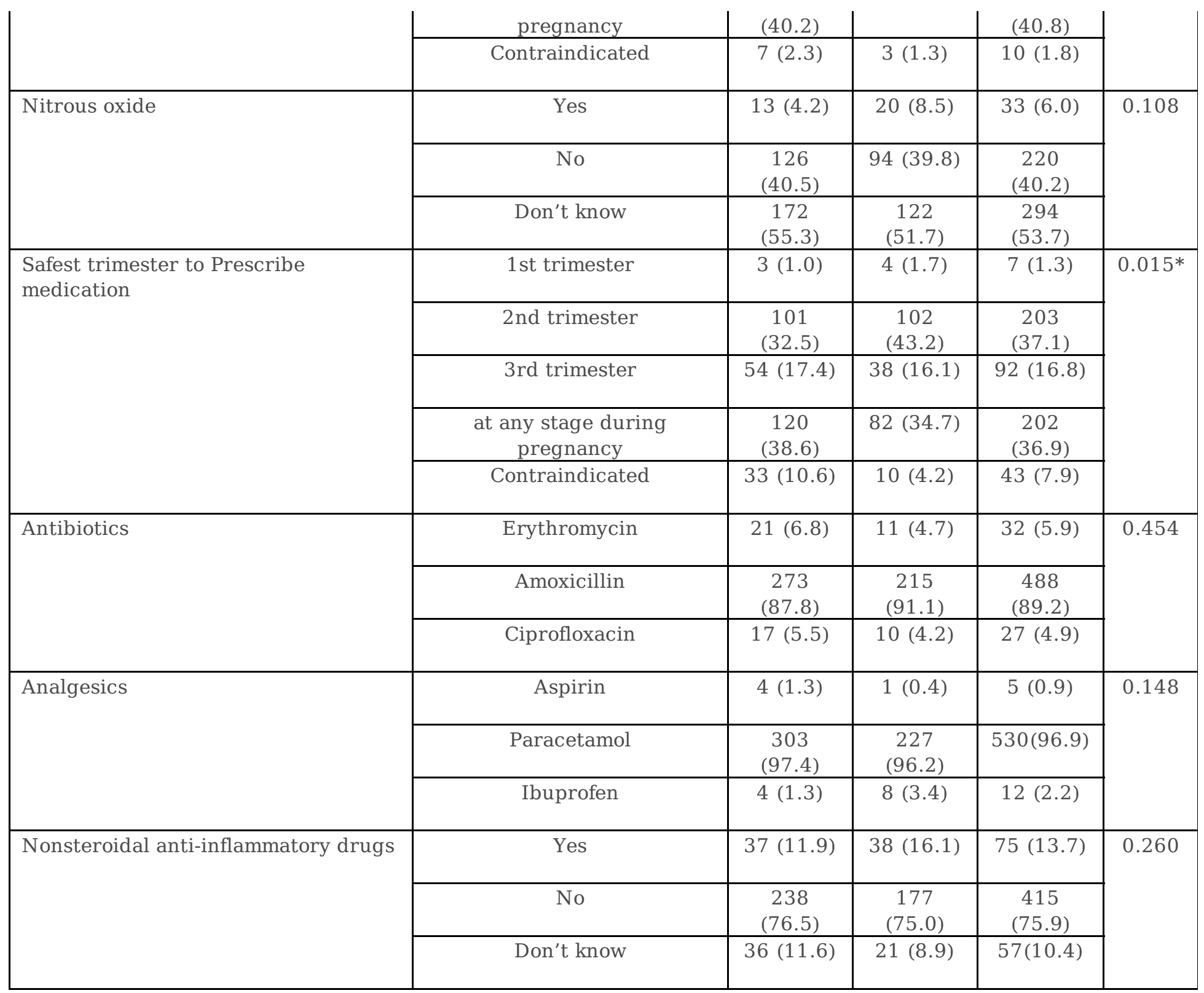

$*$ P-value $<0.05$

\section{Discussion}

Through the gestational period, pregnant women are more susceptible to develop oral changes and periodontal diseases. So, when they are presenting as patients in dental clinics, they should be treated with utmost caution as any dental procedure carried out on them may not only affect them but also the child they are carrying (18). The main focus of our study was to evaluate the knowledge, attitude, and practice of dentists in Jordan toward oral health care during pregnancy. Looking at previous studies conducted in Jordan, two cross-sectional studies closely investigated the same research question of our survey but with a different target population; the first survey was to assess the knowledge, attitude, and practice of pregnant women in utilizing the dental services, while the second one examined the knowledge, attitude, and practice of medical doctors of the association between oral health and pregnancy outcomes $(4,21)$. As a result, this study is considered the first of its kind among dentists in Jordan. 


\section{Demographic variables of the study sample}

The response rate was (54.7\%) good enough and acceptable for an online survey. More females (56.9\%) than males $(43.1 \%)$ participated in our study. The vast majority $(54.5 \%)$ were general practitioners, and high percentage of them (53.6\%) had an experience of more than five years. The present study findings showed that more than three-quarters of the participants (79.5\%) performed dental procedures for pregnant women. In contrast, $(20.5 \%)$ did not provide any dental treatment due to their doubt and hesitation. Two previous studies had similar findings; a study in Kenya revealed that $(90.0 \%)$ of the respondents had done dental procedures to expectant women whereas $(10.0 \%)$ said they had not (22). Another study in Pakistan reported that the majority of dentists (82.0\%) had no concerns regarding dental treatment for pregnant patients (3).

\section{Knowledge of dentists about the treatment of pregnant women}

With respect to the knowledge of dentists, interestingly, (91.2\%) of them considered gingival bleeding a consequence of pregnancy. This satisfying proportion aligns with various international studies, which affirmed that more than (90.0\%) of dentists recognized the association between pregnancy and bleeding gums $(23,24)$. Dentists in this survey had a limited understanding of oral health and its relation to pregnancy outcomes because $(62.5 \%)$ of them believed that there was no association between periodontal diseases and adverse pregnancy outcomes. This result indicated that dentists in Jordan had not been updated with recent studies, which assured that periodontal diseases are risk factors for APO, including preterm birth, pre-eclampsia, low birth weight, and gestational diabetes(25). Several studies in the USA reported similar perceptions, where almost (40.0\%) of dentists were uncertain about oralconditions and their effects on pregnancy (26-28).

\section{Attitude of dentists towards participating in training courses}

Only (33.1\%) were taught adequately about the same issue at their undergraduate dental collage, and more than three-quarters did not even participate in continuing education courses on the management of pregnant patients. This problem should be seriously taken into account, and management of pregnant patients should be included in dental school curricula. A similar pattern was also observed among dentists in India and Saudi Arabia, where dentists felt that they did not get enough instructions about dental treatment to pregnant women at their $\operatorname{BDS}$ courses $(29,30)$. Better findings were detected in a study conducted in Bengaluru, India, where more than half of dentists have been enrolled in educational courses related to periodontal disease and oral hygiene for pregnant patients (31). Moreover, participants who were less than 30 years old reported that they disregarded treating pregnant women more than older dentists. In general, these results are parallel with a study done in Mangalore city, India (30). 


\section{Practices of dentists regarding the treatment of pregnant women}

The hesitation among participating dentists in this research was distinctly realized about performing certain dental procedures during pregnancy. Mixed opinions were observed regarding extractions and root canal treatment. In the present study, $(60.0 \%)$ and $(72.0 \%)$ agreed to perform extractions and root canal treatment in the $2^{\text {nd }}$ trimester, respectively. So far, in the $1^{\text {st }}$ and $3^{\text {rd }}$ trimester, the dentists were more doubtful. Therefore, their opinions were distributed between consulting gynecologists, referring to specialists, or delaying the treatment until giving birth. The current findings reflect better knowledge than in a study in India, where $(69.0 \%)$ considered it safe to perform routine extractions in the $2^{\text {nd }}$ trimester, and $(56 \%)$ agreed to do root canal treatment(31). However, in other studies, the majority of dentists stated they preferred to postpone treatment till after delivery $(28,32,33)$.

When asked about the safest trimester to offer dental treatment, the opinions of dentists were aligned with ADA, APA, and New York and California guidelines and recommendations. A high percentage of our participants $(89.4 \%)$ believed that the $2^{\text {nd }}$ trimester was the preferable period to do dental procedures. In the case of radiographs, the majority of dentists felt hesitant to perform them in spite of the fact that dental radiographs were taken with the recommended neck (thyroid) collar and abdomen shields during pregnancy (19). In the present study, only (22.5\%) agreed it was safe to take radiographs at any stage during pregnancy. Data about diagnostic radiographs during pregnancy were heterogeneous among international dentists. In some countries, the proportion of dentists who were unsure of taking radiographs for pregnant women was (45.0\%), whereas in other places such as Nigeria and Australia, $(70.5 \%)$ agreed that radiographs could be performed during pregnancy $(32,34-36)$. Around $(62.7 \%)$ of our respondents followed the guidelines in placing the pregnant women in a semi-supine position. Regarding drug prescription and anesthetics administration, there was a high level of understanding and awareness when compared with other studies except for administration of nitrous oxide sedation $(3,10,35)$. The results of other studies are compatible with our research as the majority of dentists, regardless of their country of origin, preferred paracetamol and amoxicillin as the safest drugs during pregnancy $(10,32,35-$ 38). With regards to administration of nitrous oxide, more than half of the dentists did not know if it was safe to use it during pregnancy or not, although it was classified as category $\mathrm{C}$ in FDA classifications (39). It is also interesting to note that with older years of age, dentists in our sample were more conscious of prescribing medications than younger ones.

As a result, a development of clinical guidelines and treatment protocols for providing dental treatment among pregnant women in Jordan should take place. Accordingly, the new clinical guidelines and treatment protocols can be utilized by 1) antenatal care providers to coordinate oral health risk assessments and a referral system into routine antenatal care; 2 ) dental health practitioners to provide 
effective and proper treatment for pregnant women. So, these guidelines will empower health caregivers to work together as a team to improve the optimal care delivered to pregnant women, the forthcoming infants, and the entire society (19).

\section{Strengths and limitations}

Our results are derived from an online survey with all its potential strengths and limitations. The survey was anonymous and, thus, it is very likely that dentists gave correct answers without being afraid of exposing their identity. Also, they were not under any pressure to give "desirable answers" to the survey questions. Although the response rate was just about 55\%, it was more than expected given this type of surveys. Since it is difficult to believe that response was dependent on the topics of the survey (knowledge, attitudes, and practices), we believe that non-response has little effect on our results.

\section{Conclusion And Recommendations}

Given these results, our study clarifies a clear lack of knowledge among dentists about the association between adverse pregnancy outcomes and oral diseases. Likewise, the dentists' practices regarding the safe use of radiographs and other routine dental procedures do not comply with the international guidelines and evidence-based protocols. For that reason, their perceptions were below the standard level. Consequently, the data emphasized the need for developing new interventions, strategies, and training programs to help dentists practice guidelines in order to overcome the challenges and barriers which stand against offering pregnant women with optimal dental care. In addition to this, it may be more effective and beneficial to incorporate pregnancy-specific education courses in dental schools' curriculum in Jordan.

\section{List Of Abbreviations}

KAP Knowledge, Attitude, and Practice

ADA American Dental Association

WHO World Health Organization

AAP American Academy of Pediatrics

AAPD American Academy of Pediatric Dentistry

FDA Food and Drug Administration

IRB Institutional review board

RCT Root Canal Treatment

LA Local Anesthesia

APO Adverse Pregnancy Outcomes

NSAIDs Non-Steroidal Anti-Inflammatory Drugs 
SPSS Statistical Package for Social Sciences

BDS Bachelor of Dental Surgery

\section{Declarations}

\section{Ethics approval and consent to participate}

Approval to conduct the study was granted from the IRB (Institutional review board). Informed consent was obtained from the participants by messages to publish the study results.

\section{Consent for publication}

Not applicable

\section{Availability of data and materials}

All data generated during this study are included in this published article.

\section{Competing interests}

The authors declare that they have no competing interests.

\section{Funding}

Not applicable

\section{Authors' contributions}

B.A.A. and Y.S.K. conceived the ideas; B.A.A., M.D., M.A.A. collected the data; B.A.A. and Y.S.K. analysed the data; B.A.A. wrote the paper; Y.S.K., O.B.A., A.B. led the writing; B.A.A., Y.S.K., O.B.A., A.B., A.O., M.A. reviewed the paper.

\section{Acknowledgments}

The authors would like to extend their sincere thanks to all dentists who participate in this study.

\section{References}

1. Hemalatha V, Manigandan T, Sarumathi T, Aarthi Nisha V, Amudhan A. Dental considerations in pregnancy-a critical review on the oral care. Journal of clinical and diagnostic research: JCDR. 2013;7(5):948.

2. Obstetricians ACo, Gynecologists. Oral health care during pregnancy and through the lifespan. Obstet Gynecol. 2013;122(2):417-22. 
3. Wali A, Siddiqui TM, Sarwar A, Anjum A, Rao H. Perception and understanding of dental practitioners in provision of dental treatment to pregnant women in Karachi, Pakistan. Indian Journal of Dental Sciences. 2016;8(4):199.

4. Malkawi ZA, Tubaishat RS. Knowledge, practice and utilization of dental services among pregnant women in the north of Jordan. The journal of contemporary dental practice. 2014;15(3):345-51.

5. Al Habashneh R, Guthmiller JM, Levy S, Johnson GK, Squier C, Dawson DV, et al. Factors related to utilization of dental services during pregnancy. Journal of clinical periodontology. 2005;32(7):815-21.

6. George A, Johnson M, Blinkhorn A, Ajwani S, Bhole S, Yeo A, et al. The oral health status, practices and knowledge of pregnant women in south-western Sydney. Australian dental journal. 2013;58(1):26-33.

7. Kloetzel MK, Huebner CE, Milgrom P. Referrals for dental care during pregnancy. The Journal of Midwifery \& Women's Health. 2011;56(2):110-7.

8. Baskaradoss JK, Geevarghese A. Utilization of dental services among low and middle income pregnant, post-partum and six-month post-partum women. BMC Oral Health. 2020;20(1):1-9.

9. Lee RS-Y, Milgrom P, Huebner CE, Conrad DA. Dentists' perceptions of barriers to providing dental care to pregnant women. Women's Health Issues. 2010;20(5):359-65.

10. UGURLU M, ORHAN H. Knowledge, Attitude and Practices of Dentists about Oral Health Care during Pregnancy: A Cross-sectional Study from Turkey. Journal of Clinical \& Diagnostic Research. 2019;13(4).

11. Association AD. Oral health during pregnancy: What to expect when expecting. 2011.

12. Pregnancy and Dental Work/ American Pregnancy Association 2011. Available from: https://americanpregnancy.org/pregnancy-health/dental-work-and-pregnancy/.

13. Council O. Guideline on Oral Health Care for the Pregnant Adolescent. American Academy Pediatric Dentistry. 2007;33:137-41.

14. Practice ACoO. ACOG Committee Opinion. Number 299. Guidelines for diagnostic imaging during pregnancy. ACOG Committee on Obstetric Practice. Obstet Gynecol. 2004;104:647-51.

15. Law R, Bozzo P, Koren G, Einarson A. FDA pregnancy risk categories and the CPS: do they help or are they a hindrance? Canadian Family Physician. 2010;56(3):239-41.

16. Dentistry AAoP. Guideline on oral health care for the pregnant adolescent. Pediatric dentistry. 2012;34(5):153.

17. Achtari MD, Georgakopoulou EA, Afentoulide N. Dental care throughout pregnancy: what a dentist must know. Oral Health Dent Manag. 2012;11(4):169-76.

18. California DAF. Oral health during pregnancy and early childhood: evidence-based guidelines for health professionals. Journal of the California Dental Association. 2010;38(6):391.

19. Kumar J, Samelson R. Oral health care during pregnancy and early childhood: practice guidelines. New York, NY: New York State Department of Health. 2006. 
20. Vieira D, de Oliveira A, Lopes FF, Lopes e Maia MdF. Dentists' knowledge of oral health during pregnancy: a review of the last 10 years' publications. Community Dent Health. 2015;32(2):77-82.

21. Al-Habashneh R, Aljundi S, Alwaeli H. Survey of medical doctors' attitudes and knowledge of the association between oral health and pregnancy outcomes. International journal of dental hygiene. 2008;6(3):214-20.

22. Njane Peter Mwangi. KNOWLEDGE, ATTITUDE AND PRACTICE OF DENTISTS IN OFFERING DENTAL TREATMENT TO EXPECTANT WOMEN. Kenya: Univesity of Nairobi; 2008.

23. Strafford KE, Shellhaas C, Hade EM. Provider and patient perceptions about dental care during pregnancy. The Journal of Maternal-Fetal \& Neonatal Medicine. 2008;21(1):63-71.

24. Tarannum F, Prasad S, Vivekananda L, Jayanthi D, Faizuddin M. Awareness of the association between periodontal disease and pre-term births among general dentists, general medical practitioners and gynecologists. Indian journal of public health. 2013;57(2):92.

25. Komine-Aizawa S, Aizawa S, Hayakawa S. Periodontal diseases and adverse pregnancy outcomes. Journal of Obstetrics and Gynaecology Research. 2019;45(1):5-12.

26. Da Costa EP, Lee JY, Rozier RG, Zeldin L. Dental care for pregnant women. The Journal of the American Dental Association. 2010;141(8):986-94.

27. Vamos CA, Walsh ML, Thompson E, Daley EM, Detman L, DeBate R. Oral-systemic health during pregnancy: exploring prenatal and oral health providers' information, motivation and behavioral skills. Maternal and child health journal. 2015;19(6):1263-75.

28. Huebner CE, Milgrom P, Conrad D, Lee RSY. Providing dental care to pregnant patients: a survey of Oregon general dentists. The Journal of the American Dental Association. 2009;140(2):211-22.

29. Aljulayfi I, Alrusayni A, Alqahtani S, Hamam MK. Awareness of dental interns in managing cases of pregnant women in Saudi Arabia. The Saudi Journal for Dental Research. 2015;6(1):26-9.

30. James S, Rohan P. Knowledge, attitude, and practice in treating pregnant women: A questionnaire survey among dental students of Mangalore city. Journal of Indian Association of Public Health Dentistry. 2018;16(4):338.

31. Radha G, Sood P. Oral care during pregnancy: Dentists knowledge, attitude and behaviour in treating pregnant patients at dental clinics of Bengaluru, India. journal of pierre fauchard academy (india section). 2013;27(4):135-41.

32. Al-Manee A. 1 Dentist's Opinion Toward Treatment of Pregnant Patients. 2008.

33. Pistorius J, Kraft J, Willershausen B. Dental treatment concepts for pregnant patients-results of a survey. European journal of medical research. 2003;8(6):241-6.

34. George A, Ajwani S, Bhole S, Dahlen HG, Reath J, Korda A, et al. Knowledge, attitude and practises of dentists towards oral health care during pregnancy: A cross sectional survey in New South Wales, Australia. Australian dental journal. 2017;62(3):301-10.

35. Lamia A, Daou DJ. Pregnancy and Dental Treatment. Otolaryngol (Sunnyvale). 2016;6(5):268. 
36. Umoh AO, Azodo CC. Nigerian dentists and oral health-care of pregnant women: Knowledge, attitude and belief. Sahel Medical Journal. 2013;16(3):111.

37. Enabulele J, Ibhawoh L. Knowledge of Nigerian dentists about drug safety and oral health practices during pregnancy. Indian Journal of Oral Sciences. 2015;6(2):55.

38. Naidu GM, Ram KC, Kopuri R, Prasad SE, Prasad D, Babburi S. Is dental treatment safe in pregnancy? A dentist's opinion survey in South India. Journal of Orofacial Research. 2013;3(4):233-9.

39. Food and Drug Administration. Drug Safety and Availability 2019. Available from: https://www.fda.gov/drugs/drug-safety-and-availability/information-drug-class. 